\title{
Em revista o teatro ligeiro: os "autores-ensaiadores" e o "teatro por sessões" na Companhia do Teatro São José
}

\author{
Filomena Chiaradia
}

$\mathrm{N}$ a primeira década $\$$ do século $\mathrm{XX}$ a cidade do Rio de Janeiro tem como prefeito Pereira Passos, o "Haussmann Tropical", cujo plano principal de açáo se traduz em reformas radicais na cidade, onde os verbos embelezar, modernizar e civilizar estão na ordem do dia, acrescidos dos modos "rápido" e "acelerado". Tudo era premente: as obras deveriam ser feitas com tal velocidade que, como apontam vários cronistas da época, dormia-se em uma cidade e acordava-se em outra. A sensação era a de se viver num cenário, táo freqüentes eram os movimentos de deslocamento, tão velozes as mutações. E o teatro será o palco privilegiado para reapresentar, incorporando-a, a velocidade das mudanças e dos deslocamentos.

A marca inicial da construção dramatúrgica da revista de ano - que passava em revista os acontecimentos mais importantes do ano anterior - já não satisfazia aos espectadores conectados com a "modernizaçáo" dos meios de comunicação. Num espaço social e urbano acelerado, só novos modelos poderiam interessar a um público teatral também modificado. Esse momento de transiçāo e de estranhamento, em que não só o espaço urbano é alterado, mas também os hábitos cotidianos, foi propiciador de novas estruturas dramatúrgicas que se vinham formando no âmbito do "teatro ligeiro".

A expressão "teatro ligeiro", ou gêneros ligeiros, começou a ser empregada pela crítica jornalística a partir da segunda metade do século XIX quando queria referir-se aos espetáculos de revistas, burletas, vaudevilles ou mágicas. Para aqueles críticos, tais gêneros eram formas simplificadas, criaçōes nāo elaboradas, realizadas rapidamente, sem propósitos artísticos mais elevados, que se opunham ao que consideravam "teatro sério".

Nesse panorama teatral de princípio de século, a Companhia de Revistas e Burletas do Teatro São José, da Empresa Paschoal Segreto fundada em 1911 e com atuação ininterrupta até 1926 - especializou-se na encenação de revistas e burletas. Em 1919, Segreto criou a Companhia Nacional de Operetas no Teatro São Pedro, muito bem recebida tanto pelo público quanto pela crítica. Detinha ainda, nos negócios dedicados ao teatro, as atividades da Maison Moderne, uma casa de espetáculos de

Filomena Chiaradia é mestre em Teatro pela Uni-Rio e pesquisadora do Centro de Documentação da Funarte.

1 BENCHIMOL, Jaime Larry. Pereira Passos: um Haussmann tropical. A renovação urbana da cidade do Rio de Janeiro no inicio do séc. XX. Rio de Janeiro: Secretaria Municipal de Cultura, Turismo e Esportes, Departamento Geral de Documentaçáo e Informática, 1992. 
variedades, e também as do Teatro Carlos Gomes, de sua propriedade, arrendando ainda o Teatro São Pedro, hoje João Caetano, todos localizados na Praça Tiradentes. Não é de estranhar, portanto, que Brício de Abreu o intitulasse dono e senhor da Praça Tiradentes. ${ }^{2}$

A Empresa Paschoal Segreto destacou-se entre as outras empresas do gênero por ter dado às suas companhias um tratamento diferenciado, como podemos perceber neste comentário de Mário Nunes ${ }^{3}$ :

\begin{abstract}
A Empresa Paschoal Segreto é atualmente o grande esteio do teatro nacional no que concerne a peças musicadas - operetas, burletas e revistas. Mantém permanentemente abertos o São Pedro e o São José, ocupados por companhias fixas que administra diretamente, e, na verdade tem sido feliz. No segundo desses teatros nada se alterou no decorrer do ano [1921], mas no primeiro, nos últimos dois meses, adotou os espetáculos completos, levando à cena operetas vienenses completas e de grande montagem. A inovação foi recebida com gerais aplausos e o público não a desamparou.
\end{abstract}

A ampla e duradoura atuação de suas companhias mostra a presença de um teatro ligeiro que sobreviveu ds constantes crises da área cultural, com um trabalho de sucesso e um empresário extremamente criativo. Por seu caráter de longa duração e de atuação ininterrupta por mais de uma década, a Companhia de Revistas e Burletas do Teatro São José pôde proporcionar ao teatro carioca da época o suporte indispensável para o desenvolvimento e a manutenção de uma cena teatral dedicada especialmente aos gêneros revista e burleta. Ou seja, os artistas e os técnicos envolvidos nessas produçōes tiveram no palco do Teatro Sáo José um espaço efetivo de experimentação para o exercício de suas habilidades artísticas: representar, escrever, musicar, cantar, dançar, criar cenários e figurinos. Tratava-se de uma companhia rigorosamente inserida nos mecanismos comerciais, que visava o lucro, sem nenhum compromisso aparente com transformaçōes estéticas ou ambiçōes de pesquisa cênica. Mas que, em contrapartida, exigia um domínio absoluto da escrita teatral do gênero cômico e popular musicado.

\section{Autores-Ensaiadores}

Para entender os mecanismos de construção dessa cena, selecionamos os autores mais montados pela Companhia, o que significa identificar os que mais se adequaram a suas regras, isto é, aqueles que elaboraram técnicas dramatúrgicas particulares para atender a uma demanda de tal porte. As pesquisas estatísticas apontaram os nomes de Cardoso de Menezes (1878-1958) e Carlos Bittencourt (1888-1941) como os autores que tiveram maior número de montagens na Companhia. A dupla Bittencourt/Menezes foi apreciada de forma positiva pela crítica da época e em 1921 Mário Nunes ${ }^{4}$ referiu-se ao trabalho dos dois autores como "feliz parceria". Seriam, portanto, mestres do gênero, o que é confirmado, por exemplo, no trecho de artigo de Raul Rolien transcrito na Revista da S.B.A.T. (mai./jun. de 1958), publicado inicialmente no jornal Última Hora de São Paulo, por ocasiāo do falecimento de Cardoso de Menezes.

2 ABREU, Brício de. "Teatro de revista". In: O Cruzeiro, Rio de Janeiro, p. 21, 28 jul. 1956.

3 NUNES, Mário. 40 anos de teatro. Rio de Janeiro: SNT, 1956. Vol. 2, p. 4.

4 NUNES, op. cit., Vol. 2, p. 13-4. 
[...] Quem alcançou a época das grandes revistas essencialmente nacionais, anteriores à influência "bate-taclan", revistas com texto a base de comicidade inteligente, maliciosa sem pornografia e a pornofonia de "toalete" público, tão em voga hoje, deve realmente lamentar o desaparecimento de um dos maiores revistógrafos brasileiros que, com Bastos Tigre, Carlos Bittencourt, Raul Pederneiras, Luiz Peixoto e outros, formaram o grupo de ouro do humorismo carioca.

Partindo da leitura dos textos dessa parceria montados na Companhia do Teatro São José 5 podemos perceber os indícios de uma cena teatral e o quanto os seus autores estavam ligados a ela, assumindo muitas vezes o papel de "autores-ensaiadores". Assim como foi possível a Paul Zumthor ${ }^{6}$ (guardadas as devidas proporções, as distâncias pertinentes e as diferentes relaçóes culturais envolvidas) encarar os textos medievais mais como registros de uma oralidade e de uma performance que como produtos exclusivamente literários, podemos verificar também em que medida os nossos textos de revistas e burletas, produzidos indiscutivelmente em fun- ção de uma exigência cênica, apresentam características peculiares e nada simples ou ligeiras.

Antes de nos determos no que caracteriza esses autores como "autores-ensaiadores", devemos saber que a figura do "ensaiador" era elemento importante das companhias daquele período. Alguns significativos nomes do teatro da época desempenharam essa função na Companbia do Teatro São José: Leopoldo Fróes, por um curto período, em fins de 1914 e início de 1915, e Luiz Peixoto, com passagem igualmente rápida, em 1923. Permaneceu mais tempo na função o português Eduardo Vieira, substituído depois por Isidro Nunes. Ao ensaiador cabia, antes de tudo, marcar o espetáculo:

Competia-lhe, em particular, traçar a mecânica cênica, dispondo os móveis e acessórios necessários à ação e fazendo os atores circularem entre eles de modo a extrair de tal movimentação o máximo rendimento cômico ou dramático. Papel bem marcado, dizia-se, meio caminho andado. ${ }^{7}$

O trabalho de cena do ensaiador no palco do teatro ligeiro, voltado fundamentalmen-

5 Foram trabalhados 20 textos manuscritos e/ou datilografados, localizados, em sua maioria, na coleção Paschoal Segreto, sob a guarda da Divisão de Música e Arquivo Sonoro da Biblioteca Nacional, onde obtive permissão especial de acesso para essa pesquisa, pois trata-se de coleção ainda não tratada tecnicamente: CARDOSO DE MENEZES: Só pra moer (1918) - revuette, de parceria com Alfredo Brito e Octávio Tavares; Angu à baiana (1918) - burleta, de parceria com J. Miranda; Confessa, meu bem (1919) - revista; Gato, baeta e carapicú (1920) - revista carnavalesca. CARLOS BITTENCOURT: Forrobodó (1912) - burleta, de parceria com Luiz Peixoto; Depois do forrobodo (1913) - burleta (só o primeiro ato); Morro da favela (1916) - burleta, de parceria com Luiz Peixoto; Dança de velho (1916) - burleta de costumes carnavalescos, de parceria com Luiz Peixoto; Garanto a zona (1917) - revista, de parceria com Inácio Raposo; A flor de Catumbi (1918) - burleta carnavalesca, de parceria com Luiz Peixoto. MENEZES-BITTENCOURT: $O$ pé de anjo (1920) - revista; Quem é bom já nasce feito (1920) revista; Réco-Réco (1921) - peça carnavalesca; Segura o boi! (1921) - revista; Olelê!Olalá!'(1922) - revista carnavalesca; Olha o Guedes! (1924) - revista; Alô, quem fala? (1924) - revista; Agüenta, Felipe! (1924) - revista; Se a moda pega (1925) - revista; Bahiana, olha pra mim (1926) - revista carnavalesca.

6 ZUMTHOR, Paul. A letra e a voz: a "literatura" medieval. São Paulo: Companhia das Letras, 1993.

7 PRADO, Décio de Almeida. O teatro brasileiro moderno. São Paulo: Perspectiva: Edusp, 1988. p.16. 
te para as marcaçóes, é tão assentado no pressuposto da fragmentação como o são o texto e a música operantes nos espetáculos. A distribuição das "partes" dos textos, a presença das tabelas de ensaios, o trabalho de marcação, enfim, toda a prática operada para a montagem desses espetáculos é ditada pela mesma técnica de sua escrita dramatúrgica, ou seja, por recursos da não-linearidade e pelo exercício de sucessivas fragmentaçóes em unidades de composição. Partindo dessa compreensão, que não distancia escrita dramatúrgica e encenação, estamos encarando essas montagens como parte importante do que viria a ser a moderna cena brasileira, sendo não só o ensaiador um embriāo de futuras posturas de direção mas também toda a prática dos gêneros ligeiros um espaço gestor de técnicas e métodos para uma cena diferenciada, inclusive para esse exercício desenvolvido por Bittencourt e Menezes como "autores-ensaiadores". Estamos seguindo e concordando com o caminho apontado por Rabetti $^{8}$ ao refletir sobre o "ideário de rupturas" que prevaleceu na história de nosso teatro, que persiste na prática de exclusão e não de reelaboração, negando, portanto, todo trajeto de longa duração e identificador de tradiçóes culturais que, em geral, são classificadas como "velha guarda", passada, obsoleta.

A percepção do trabalho integrado da "feliz parceria", que não se limitava à mera função de escrever os "roteiros" para os espetáculos de revistas ou burletas, mas consistia antes em elaborar essa escrita dramatúrgica a partir da experiência concreta de sua performance, faz com que esses textos indiquem vários caminhos percorridos na cena. A análise das revistas e burletas da parceria revela que o melhor exemplo da participação efetiva desses autores na cena é dado, principalmente, por meio das rubricas dos textos, fontes esclarecedoras da mediação entre autor e cena. ${ }^{9}$ Suas minuciosas indicaçóes vão desde a detalhada descrição de cenário até as marcaçōes de movimentação do elenco e do coro, revelando que seus autores escrevem as peças imaginando-as no palco e tentando colocar no corpo de seus textos todas as impressões que deverão ser concretizadas na cena.

Notamos que, em algumas rubricas, os autores assinalam que determinadas tarefas devem estar a cargo ou do cenógrafo ou do ensaiador, mas não no sentido de que elas sejam inerentes a um ou a outro. É como se os autores concedessem a esses profissionais a liberdade de criar alguma marca ou elemento cenográfico sobre suas obras. No caso específico do ensaiador, seu espaço de criação tende a limitar-se às movimentaçōes mais corriqueiras que, de tão usuais, nem precisam ser registradas em rubricas. Mesmo assim, no segundo ato de Gato, Baeta e Carapicú (1920) encontramos a seguinte rubrica:

[...] formam grupos distintos nos quais sempre sobressaem as cores dos pavilhōes dos três

8 Podemos citar especialmente o artigo publicado na Folhetim - RABETTI, Beti. História do teatro como história da cultura: ideários e trajetos de uma arte entre rupturas e tradiçóes. Folhetim, Rio de Janeiro, n. 2, p. 27-36, 1998. - mas devemos ressaltar que a atuaçăo da Prof ${ }^{2}$. Dr ${ }^{a}$. Beti Rabetti como coordenadora do Projeto Integrado: Um estudo sobre o cômico: o teatro popular brasileiro entre ritos $e$ festas, no curso de Artes Cênicas da Uni-Rio (graduação e pós-graduaçáo) e como orientadora e professora, tem se pautado por vigorosas discussōes que fundamentam importantes reflexóes sobre a cena teatral brasileira.

9 “[...] no texto didascálico encontra-se a voz do próprio autor." In: TORRES, Walter Lima. O título: primeiro sentido do texto teatral. Folhetim, Rio de Janeiro, n. 2, p. 37-50, 1998. 
grandes grupos carnavalescos, mudando de marcas e conseqüentemente de cores. Esse bailado fica "ad libitum" do senhor ensaiador, de acordo com a música que for escrita. (Cena 5, Ato II; grifo nosso)

Mas nem sempre esse "ad libitum" significa autonomia de criação. Ao contrário, parece-nos que nossos autores atribuem aos cenógrafos e ensaiadores o papel de executantes de suas criaçóes, que são descritas de forma sempre detalhada:

A cena representa um salão fantástico, ad libitum do artista cenógrafo que o executar. Ao fundo, bem no centro, um grande globo terráqueo. Este globo está sempre em contínua rotaçáo sendo internamente iluminado, deixando ver, desenhado, os cinco continentes, isso geograficamente. A direita e esquer$\mathrm{da}$ com passagens para personagens. Ao ser feita a mutação estão em cena Terras e Águas, representados pelo corpo coral. Igualmente encontram-se em cena Chico e Diabinho. Chico está boquiaberto. O globo terráqueo deve permitir a saída de personagens e ficar colocado de maneira a poder descer até o meio $\mathrm{da}$ cena, onde, completando a apoteose do ato, abrirá em cinco gomos, em cada um dos quais terá uma mulher reclinada, representando cada uma delas a Europa, Ásia, África, América, Oceania. Muita luz. (Confessa, meu bem (1919) Quadro II, Ato I; grifo nosso)

Outra rubrica, de Olelê!Olalá! (1922), apresenta a sofisticação a que chegaram os autores no objetivo de verem em cena exatamente o que haviam imaginado:

(Quadro II, Ato I) A cena representa o interior de um estabelecimento de pianos e música, havendo a esquerda baixa um pequeno balcão, sobre o qual Carioca está trepado a dançar e a distribuir impressos a populares de ambos os sexos. A direita, portas de co- municação para a rua. Ao fundo, bem no centro, ocupando ele sua largura, quase que toda a cena, um grande piano que obedece em absoluto a "maquete" fornecida pelos autores da revista. Ainda ao fundo, no alto, uma taboleta com os seguintes dizeres: "Ao Piano Mágico" - "Carioca \& Cia." - Músicas que mexem com os nervos". (grifo nosso)

No decorrer da cena vão sendo indicadas, sempre por rubricas, as "mágicas" de um piano que faz surgir de seu interior vários grupos de coristas, apresentando diversos números musicais coreografados. A participação dos autores na colocação em cena desses gêneros por meio dessa maneira particular de escrita dramática parece-nos evidente, sugerindo-nos, às vezes, sua própria atuação na função de direção de atores.

Em Agüenta, Felipe! (1924), por exemplo, podemos perceber, por meio das rubricas, as indicaçōes precisas pelas quais os autores procuram dirigir a movimentação e as intençōes do personagem. A cena se constrói em torno do casal de portugueses Fernando e Adelaide, donos de uma pensão. $O$ marido, tentando evitar qualquer possibilidade de traição por parte da esposa, instala em seu corpo um mecanismo de alarmes sonoros, prontos a disparar mediante o mais suave toque.

Fernando - [...] O Adelaide! [...] estás com a ligação feita?

Adelaide - Pois entāo? Não havera de estar? Fernando (desconfiado) - Hum! (chegando-se a ela) Deixa-me ver...O seguro morreu de velho...(abraça-a de frente e ouve-se o toque de uma buzina de automóvel) Pela frente estou garantido....(abraça-a de maneira que os braços abranjam as cadeiras e a parte posterior, ouvindo-se o toque de uma "sereia" de vários sons) Continuo a estar sossegado... (apalpalhe os braços e ouvem-se várias campainhas elétricas) Muito bem! Com essa ligação toda, eu tenho certeza de que ninguém te pode tocar, sem que eu saiba! (QuadroI, Ato II) 
Mas é em relato de Cardoso de Menezes ${ }^{10}$ que verificamos a real participação desses autores nas montagens dos espetáculos, o que sem dúvida garantia a obediência às indicações das rubricas. Eles se responsabilizavam não só pela seleção das músicas, mas também pela composição das letras e participação nos ensaios, tanto nos especificamente musicais quanto nos outros. Menezes conta que, em geral:

\begin{abstract}
$\mathrm{Na}$ nossa parceria o Carlinhos incumbia-se igualmente de tratar com os empresários, dos direitos autorais, sempre maiores que os da tabela desta Sociedade, das festas dos autores, reclames nos jornais, tudo enfim, que dissesse respeito a finanças, enquanto eu me encarregava da distribuição dos "papéis", ensaios de poema e música, cenários e guardaroupa, acomodaçáo de brigas e ciumadas entre artistas, em consequiência de papéis maiores e melhores $[\ldots] .{ }^{11}$
\end{abstract}

Essa citação revela detalhes preciosos sobre o exercício teatral de autores do "gênero ligeiro". Torna evidente o responsabilizar-se por tarefas que, acreditávamos, pertencessem ao ensaiador ou ao diretor de cena, ao cenógrafo, ao figurinista e até ao empresário (como os "reclames", por exemplo), e que se não eram executadas integralmente pelos autores, seriam certamente acompanhadas de perto por eles. Neste último caso, a relação dos autores com os demais profissionais integrantes da equipe $d a$ companhia era intensa e permanente: participavam das decisóes sobre a montagem do espetáculo ao mesmo tempo em que decidiam sobre a distribuição dos papéis, pois criavam seus personagens visando a cada intérprete da companhia:

Quando escrevíamos as nossas revistas, como sempre destinávamos os diversos "papéis" para determinados artistas; como pela constância de serem eles intérpretes dos personagens que idealizávamos, quando líamos os diferentes "quadros", sem que soubéssemos a razão, o por que, insensivelmente imitávamos o falar dos referidos artistas, dando aos diálogos a entonaçáo de voz dos intérpretes! ${ }^{12}$

Essa ordem de envolvimento integral com a cena e seus intérpretes é um dos elementos que permite distinguir esses autores como mestres de uma escrita teatral particular. Sabese, por exemplo, que durante o processo de criação de uma peça os autores liam algumas cenas para várias pessoas, antecipando a presença do público. Procuravam também diversificar a platéia pois, segundo Menezes ${ }^{13}$, a leitura era feita [para] os intelectuais e [para] o Zé-povinho!, antes mesmo de levar a peça para os ensaios ou publicá-la. Criava-se, assim, um espaço de avaliação prévia da cena em ato, o que proporcionava aos autores não só uma amostra de seu efeito, como também a coleta de opinióes que possivelmente se traduziriam em novas possibilidades criadoras para seus roteiros iniciais. A preocupação com essa avaliação prévia da cena escrita evidencia-se também nos comentários de Carlos Bittencourt, em 1921, a respeito do texto "em parceria", reforçando as observaçōes relatadas por Menezes:

10 MENEZES, Cardoso de. "Sessáo de homenagem a Carlos Bittencourt". In: Boletim da SBAT, Rio de Janeiro, n. 207, p. 11-16, set. 1941.

11 MENEZES, op. cit., p. 14.

12 Id., Ibidem.

13 Id., Ibidem. 
[...] Somos amigos velhos e trabalhamos com muita confiança um no outro. Quase sempre um encontro na rua e surge um bom título, para estímulo inicial. Fazêmo-nos duas ou três visitas, sendo que a nossa maior preocupação é o quadro-eixo da revista, isto é, o que nós precisamos que cause grande hilaridade. E depois os tipos cômicos que devem atravessar a peça, pois como deve ter notado, ultimamente abrimos mão dos fatigantes compères, para conduzirmos, através de cenas jocosas, algumas personagens, ligadas ao fio do enredo.[...]. E assim vamos completando a revista até o final do $1^{\circ}$ ato e não vamos além sem que seja posta em ensaios. A verdade é que não nos sentimos bem sem a prova dos ensaios. [...] Quase sempre quem trata de acompanhar os ensaios é o Cardoso, porque sendo mais velho, consegue ser mais respeitado. No São José, onde nossas peças conseguem demorarse no cartaz, temos a grande preocupação de escrever grande número de pequenos papéis, mas com margem de efeito para os artistas, porque a companhia é grande e as três sessões não dão ensanchas para grandes tiradas."14 (grifo nosso)

Por meio desses depoimentos e das rubricas, detentoras de um verdadeiro universo de informaçóes sobre a cena, podemos perceber que esses autores estavam absolutamente comprometidos com a prática teatral. Ao indicar detalhadamente um cenário, ao descrever um figurino, ao orientar a movimentação e os estados de ânimo dos personagens, as rubricas refletem a presença do autor em cena, como regente de uma escrita que só se compreende como escritura cênica, na medida em que só se completa inteiramente no espetáculo, com a assistência de seu público.

\section{Texto de Cena}

Tivemos a oportunidade de comparar dois exemplares do texto Quem é bom já nasce feito (1920): um deles localizado na Coleção Paschoal Segreto (Divisão de Música/Biblioteca Nacional), manuscrito e assinado pelo ponto da Companhia, o senhor White e que chamamos de "texto de cena"; o outro encontrado na Coleção da 2a Delegacia Auxiliar da Polícia do Distrito Federal ${ }^{15}$ (Arquivo Nacional), datilografado, que chamamos "texto original". Observamos entre eles a exclusão ou o deslocamento de quadros e cenas, além de vários cortes nas falas das personagens.

A comparação confirmou a qualidade de movência das produçōes dramáticas, e a partir daí tentamos observar os objetivos a que as mudanças atendiam. No trabalho de cotejo dos dois textos, observamos que, de um modo geral, os cortes objetivavam, prioritariamente, uma redução no tamanho da peça, "enxugando" os quadros e cenas e tornando os diálogos mais ágeis e diretos. Um critério rigoroso para a escolha dos cortes não pôde ser percebido, mas é indiscutível a tendência para a retirada de falas ou de cenas com maior teor de crítica social. Houve também algumas alterações no diálogo para torná-lo mais malicioso - mais "pimenta", para usar o jargão dos revistógrafos. De qualquer forma, não encontramos exemplos de mudanças estruturais que comprometessem o sentido geral ou o fio condutor da peça.

Observamos no exemplar do ponto, que guarda mais proximidade com a montagem, a supressão integral do Quadro I do Ato II, o mais contundente da revista, por tratar da questão de moradia. O quadro se passa numa casa de cômodos, evidenciando, com passagens cômicas, todas as dificuldades de convivência e as incon-

14 NUNES, op. cit., Vol. 2, p. 13-4.

15 Todos os textos teatrais deste período, passavam por esta $2^{a}$ Delegacia, onde se exercitava a funçáo da Censura; que determinava a liberação ou não do texto para montagem. 
veniências resultantes desta confusa, e comicamente propícia, "alternativa habitacional", que resulta da situação de precariedade daqueles que não podem pagar o aluguel de uma casa e também da pouca disponibilidade de ofertas de moradias de aluguel na cidade. Uma observação feita em crítica ao espetáculo, por ocasião de sua estréia, nos revela que o quadro da casa de cômodos foi encenado e, inclusive, elogiado: "[...] tendo cenas que representam uma casa de dois andares que dá ensejo a truques interessantes." 16

O que podemos concluir, a partir destas informaçóes, e observando que no exemplar do ponto havia a data de março de 1921 , é que este manuscrito se refere a uma reprise da peça, de 1921.17 (Nunes, 1956, Vol. 2: 32). Nesta medida, mais uma vez o corte do quadro permite a movência do texto, que atende à cena e dela se aproxima por meio de sucessivas montagens e da relação que estabelece com seu público. Assim reforçamos a hipótese de uma dramaturgia ligeira não porque precária ou insuficiente, mas porque imediatamente construída para a cena, e que leva em conta o tempo desta própria cena. O que queremos dizer é que a agilidade de uma cena define sua inclusão ou exclusão na montagem do texto. $\mathrm{Na}$ medida em que o quadro da casa de cômodos sugere a construção cênica de dois pavimentos, isto demanda não só o tempo de montagem e desmontagem mas também o tempo requerido pelo deslocamento dos atores durante as cenas. Tendo que optar entre um quadro que possua bons momentos de comicidade e outro que também guarde boas piadas, sem necessitar de tantas mudanças cenográficas, o autor escolhe o segundo, especialmente no caso de reprise, quando se trata de um espetáculo "de passagem", que reitera o caráter de ligeireza e velocidade entre uma montagem e a próxima.

\section{Teatro por Sessōes}

A ligeireza e a velocidade definem um modo diferenciado de tratamento das produçōes espetaculares. Para adequar-se a elas, Paschoal Segreto adota aquela que foi considerada a mais polêmica estratégia para atrair público: o famoso sistema de "teatro por sessōes", isto é, espetáculos breves, com duração de uma hora e quinze minutos, apresentados em três sessóes diárias: $19 \mathrm{~h}, 20: 45 \mathrm{~h}$ e $22: 30 \mathrm{~h}$. Operado de forma estável pela Companhia do Teatro São José até o momento de sua dissolução, em 1926, o sistema pôde ser aprimorado a ponto de se constituir elemento determinante de sua caracterização estética. Pois o que se verifica é que o teatro por sessóes desencadeia mudanças na própria estrutura da obra teatral. Pode-se dizer que sua implantaçáo em quase todas as companhias teatrais cariocas a partir de 1911, especialmente as que se dedicam ao teatro popular musicado, aproxima esses espetáculos do contexto embrionário da cultura de massa e da indústria cultural, além de criar uma série de polêmicas.

O melhor exemplo das polêmicas suscitadas pela emergente prática do teatro por sessóes é o de Viriato Correa, que narra experiência significativa com a companhia de Paschoal, quando sua primeira peça de teatro, Sertaneja, é encenada no Teatro São José. Como a peça de Viriato estaria longa demais para o novo sistema, Paschoal vai até a casa do autor para convencê-lo a diminui-la em pelo menos trinta minutos. Resumindo a peleja que decorre da negativa do dramaturgo, eis o relato que pode nos desvendar alguns procedimentos de ordem técnica necessários às novas práticas da cena teatral naquele ano de 1915.

- Se eu cortar a peça, Paschoal, quinze ou dez minutos que sejam, desaparecerá a "Ser-

16 DA PLATÉIA. A Noite, Rio de Janeiro, p. 7, 18 out. 1920.

17 NUNES, op. cit., Vol. 2, p. 32. 
taneja" que ontem o público aplaudiu. Será outra peça que o público pode não aplaudir. [...] Acudiu-me, então, um argumento que me pareceu decisivo.

- Paschoal, que é que está pintado naquele quadro? [...]

- Uma espanhola.

- Mas se eu tirar dessa espanhola as sandálias, a mantilha, as castanholas, os olhos quentes, o moreno do rosto, o ar "saleroso", fica uma espanhola?

Ele levantou-se da cadeira com a mais doce expressão deste mundo:

- Mas não é isso que estou pedindo. O que eu quero é que você me faça uma espanhola mais magra. ${ }^{18}$

A redução feita nos textos para que "caibam" em espetáculos de uma hora e quinze, quando o que dominava até então eram espetáculos de pelo menos duas horas, gera as mais contundentes críticas feitas ao teatro por sessões. No entanto, o trabalho dramatúrgico de adaptação determina uma maior destreza do autor no alcance da síntese, sem necessariamente empobrecer o texto, levando-o pelo caminho "mais fácil" das piadas repetidas infinitamente. A verdade é que o teatro por sessões determinou uma cena mais ágil, sintética, sem excessos. Uma cena mais moderna ou, para mais uma vez usar a citação de Viriato Correa, uma cena como uma espanhola mais magra.

Compreendemos que os gêneros do teatro ligeiro, por todas as suas características maleabilidade de inclusão e exclusão de quadros, combinação de repertórios de situaçóes e tipos cômicos disponíveis, escrita calcada na performance e na resposta do público - permitiram, por meio do sistema de teatro por sessóes, importantes experimentaçóes artísticas e artesanais no campo do teatro brasileiro, orientadas sobretudo para uma escrita dramatúrgica que, necessariamente, teve que desprender-se dos padróes literários impostos pelas escolas romântica e realista. Entendemos que essas criaçóes dramatúrgicas jamais partiram de pressupostos literários reguladores, fazendo parte de sua elaboração, sobretudo, o critério de exigência da complementaridade cênica. A cena, em resumo, teria sido o grande autor desses gêneros teatrais.

A nosso ver, o conjunto de comentários críticos do período assinala questōes fundamentais para o sistema de teatro por sessóes: a necessidade de especialização por parte dos autores, isto é, a exigência de domínio técnico diferenciado para criar textos adequados a um novo tipo de produção cênica; o esgotamento físico e artístico dos artistas, gerado pelo estabelecimento de uma intensa rotina de trabalho, sem folga semanal; a necessidade de atender à demanda crescente de produçōes; a tentativa, nos melhores casos, de manter, ao mesmo tempo, qualidade artística e interesse do público.

Por outro lado, náo podemos negar que o incremento do trabalho teatral proporcionado pelo teatro por sessóes cria condiçóes para o aprimoramento técnico não só de autores, como também de atores e de outros artistas. Do ator, por exemplo, passa a se exigir o domínio de especializações: não apenas o canto e a dança são indispensáveis, como também a exercício de possíveis vocaçóes histriônicas. A própria rotina de ensaios e de três ou quatro sessóes por noite, sem nenhum dia de folga, acaba por exigir desses artistas a invençáo de uma espécie de "caixinha de surpresas", especialmente para o espetáculo da última sessão. Essa terceira sessão guarda, aliás, algumas importantes revelaçōes sobre o teatro do período, como a que narra Mário Nunes ${ }^{19}$, e que consideramos uma das

18 CORREA, Viriato. "Paschoal Segreto: curiosa figura de empresário". In: Revista Comoedia, Rio de Janeiro, n. 4, p. 68, out./nov. 1946. 
mais interessantes por mostrar uma suspensāo temporária na opiniāo dominante do crítico que, sempre contrário ao sistema das sessōes, aparentemente não resiste a seus "encantos", quando, em 1919, diz:

[...] Representava-se a revista "Contra a mão". A orquestra toca a introdução de um número que Otília Amorim devia cantar. Otília não estava disposta, ao que parece, olhou desanimada para o auditório escasso, sorriu e ficou muda. O maestro pensando ser distração da atriz repete o intróito e Otilia, nada! Não queria cantar, e a orquestra prossegue sozinha. Então João de Deus, não se conteve e, com aquele tom de molecagem que tão bem vai aos papéis que, por vezes, interpretara, disse: - Assim, minha nêga, castiga, castiga esses trouxas que vieram à $3^{\mathrm{a}}$ sessáo...

E o teatro riu, riu com tamanho estrépito, que parecia estar completamente cheio!

Somos, dessa noite em diante, dos que não perdem a 3a sessão do Teatro Sáo José..."

O fato é que quando se aceleram demasiadamente os espetáculos ou se amplia o número das sessóes o próprio sistema se descaracteri$\mathrm{za}$, gerando desnivelamento entre agilidade e qualidade artística, sacrificada em favor das necessidades comerciais. A extenuante rotina acaba por alterar o andamento dos espetáculos, aspecto bastante condenado pelos críticos da época, especialmente pelo próprio Mário Nunes.

Evidentemente nem todos os autores da época lograram êxito nesse exercício de síntese $e$ de agilidade. E a grande tarefa que teve de ser enfrentada pelos estudiosos e críticos teatrais, que de várias formas protestaram contra o teatro por sessóes, revelou não só o apego às for- mas consagradas, a um modelo de teatro considerado "clássico" e que os impedia de analisar uma nova cena (que, para eles, refletia apenas uma "mutilação" e um mero entretenimento), como também a dificuldade em encontrar autores que, de fato, tivessem alcançado êxito no empreendimento.

Mais importante que constatar esse limite é verificar que um dos resultados do aumento do número de sessóes diárias é o barateamento do preço dos ingressos. Por meiø desse sistema, paulatinamente é incorporada ao espetáculo uma camada de público que, até então, não tivera oportunidade de ir ao teatro. Tal "popularização" é parte de uma mentalidade empresarial que começa a despontar em vários campos de atividades, como inevitável necessidade de acompanhamento das mudanças impostas pelo avanço tecnológico. Como os cronistas e jornalistas, também os autores teatrais estão voltados para o mercado, onde os interesses comerciais dos empresários determinam grande parte das produçôes.

A cultura popular urbana que contextualiza essa produção teatral equaciona, de certa forma, as relaçōes entre a cultura tradicionale os meios de comunicação de massa. ${ }^{20} \mathrm{~A}$ Companbia do Teatro São José espelha os propósitos de sua empresa de dinamizar a produção dos espetáculos, por meio de apresentaçōes por sessões, aumentando quantitativamente seu público, assim como possibilitando também sua diversificação. Se levarmos em conta sua durabilidade, podemos pensar que a cooptação do heterogêneo público freqüentador da sala do São José e sua participação decisiva no andamento dos espetáculos podem nos remeter à configuração dessas cenas teatrais como produçōes "em série", apontadas para um movimento

20 CARVALHO, José Jorge de. "O lugar da cultura tradicional na sociedade moderna". In: Seminário Folclore e Cultura Popular: as várias faces de um debate. Rio de Janeiro: IBAC, CFCP, 1992. p.23-38 (Encontros e Estudos; 1). 
inicial de cultura de massa e anunciando a possibilidade de circulação entre faixas culturais diferenciadas.

De acordo com Carvalho ${ }^{21}$, é preciso estar atento para uma espécie de estrutura de pensamento um tanto "mítica", criada em torno da indústria cultural, que reproduz a idéia do "mito da degenerescência da cultura" a partir do entendimento de que o artista não resiste $\grave{a}$ sedução implacável do mercado. $\mathrm{O}$ autor propōe, ao contrário, uma reflexão que busque o ponto de vista das formas plurais para a produçâo cultural, pois, "[...] nem tudo de mau gosto que a indústria cultural oferece desapareceria se pudéssemos intervir e impedi-la de continuar atuando na sociedade, pelo fato de que certas manifestaçoes culturais respondem a necessidades de expressäo humanas diversas, quase atemporais, como o grotesco, a comicidade, a inversão simboblica, a caricaturização do real, etc. [...]" (Carvalho, J.J., 1992: 33; grifo nosso).

Dessa maneira, considerar o teatro ligeiro parcela significativa e participativa da construção do teatro brasileiro é positivar, em parte, sua existência. $\mathrm{E}$, se ainda assim pairasse alguma dúvida, Néstor Canclini'22 conclui:

$\mathrm{Na}$ verdade, toda a arte supōe a confecção dos artefatos materiais necessários, a criaçăo de uma linguagem convencional compartilhada, o treinamento de especialistas e espectadores no uso dessa linguagem e a criação, experimentação ou mistura desses elementos para construir obras particulares.

21 CARVALHO, op. cit., p. 30 e ss.

22 CANCLINI, Néstor García. Culturas hibridas: estratégias para entrar e sair da modernidade. Sáo Paulo: Edusp, 1998, p. 38. 